\title{
Polyamide 6-Long Glass Fiber Injection Moldings
}

\author{
H. BIJSTERBOSCH* and R. J. GAYMANS
}

\author{
Twente University \\ 7500 AE Enschede, The Netherlands
}

\begin{abstract}
The injection molding ability of long glass fiber reinforced polyamide pellets was studied. The injection moldable materials were produced by a melt impregnation process of continuous fiber rovings. The rovings were chopped to pellets of $9 \mathrm{~mm}$ length. Chopped pellets with a variation in the degree of impregnation and fiber concentration were studied. The injection molded samples were analyzed for fiber concentration, fiber length, and fiber orientation. Dumbbell-shaped tensile bars were made to evaluate the mechanical properties. The fibers in the tensile bars had a high orientation in the flow direction and minor fiber concentration gradients were observed. The fiber lengths decreased with fiber concentration from 1.6 $\mathrm{mm}$ for a $2 \mathrm{vol} \%$ to $0.6 \mathrm{~mm}$ for a $25 \mathrm{vol} \%$ system. The tensile and impact properties increased considerably with fiber concentration. A low degree of impregnation in the pellets of the fibers resulted in somewhat lower tensile and impact properties.
\end{abstract}

\section{INTRODUCTION}

$\mathrm{L}$ ong fiber injection molding pellets consist of parallel strands of reinforcement, impregnated with a thermoplastic matrix. With these long fiber pellets products can be made with a much higher residual fiber length than was previously possible with extrusion compounded pellets (1). Increasing the fiber length in the product generally increases the stiffness, strength, and toughness.

To attain long fibers in the product, injection molding of long fiber materials must be performed with minimum work. In this way, fiber degradation is minimized (2-5). The fiber degradation can also be lowered if the flow is in bundles (6-8). These bundles are domains of locally aligned fibers. The bundles break up in high shear-stress regions, e.g., during plastization or flow through small openings. Surviving small bundles can some times be observed in the core (center) of the test sample $(9,10)$.

Fiber length and fiber concentration can vary significantly between the skin and core of injection molded long fiber pellets $(11,12)$. The fiber concentrations in the core of samples molded from a long glass fiber reinforced polyamide 66 has been found to be double that of in the skin. The observed fiber concentration differences are larger than in extrusion compounded short fiber systems $(13,14)$. Also the size of

${ }^{*}$ Present address, Holec Systems and Components, PO Box 25, 7550 AA Hengelo. The Netherlands. the core becomes larger with increasing fiber length and concentration (12). To attain a high degree of wetting of the fibers in the injection molded product, the degree of impregnation of the long fiber chips does not have to be high $(15,16)$.

The properties of fiber reinforced systems depend on fiber concentration, fiber orientation, fiber length, and fiber-matrix adhesion. Long fiber systems have better tensile properties and in particular impact properties. The major energy absorbing mechanism in fiber reinforced systems is fiber pullout (17). In systems where the fiber length is longer than the critical fiber length fiber fracture takes place.

We studied the effect of fiber concentration and degree of impregnation of long fiber pellets on the fiber length, fiber concentration fluctuations, and fiber orientation in the injection molded sample. Next studied was the influence of fiber length on the tensile and impact properties. We also studied whether with a master batch the same properties can be obtained as with an undiluted system.

\section{EXPERIMENTAL}

\section{Materials}

The materials used are an injection moldable grade polyamide 6 (Akulon M223D) supplied by DSM, The Netherlands, and a glass fiber roving (14P75) provided by PPG, The Netherlands. The glass fibers had a diameter of $20 \mu \mathrm{m}$ and were treated with a proprietary sizing $(0.2 \mathrm{wt} \%)$. 


\section{H. Bijsterbosch and R. J. Gaymans}

\section{Long Fiber Injection Molding Materials}

Injection molding materials were produced with a melt impregnation set-up $(18,19)$.

Materials with a poor impregnation were made by pulling the glass roving through a melt at $265^{\circ} \mathrm{C}$ at a line speed of $20 \mathrm{~m} / \mathrm{min}$ without using pins. The bundle was coated with the polymer and the degree of impregnation was $<10 \%$. Materials with a good impregnation were made by pulling the glass roving over five spreader pins at $290^{\circ} \mathrm{C}$ and a speed of 10 $\mathrm{m} / \mathrm{min}$. The degree of impregnation was $>80 \%$ (18). The fiber concentration of pellets was changed by changing the diameter of the stripper die. The rod that left the die was cooled with water and subsequently chopped into pellets $(9 \mathrm{~mm})$ with a rotating blade cutter.

\section{Injection Molding Series}

Series A. Pellets with $16 \mathrm{wt} \%$ glass ( 10 vol\%) with a low degree of impregnation $(<10 \%)$ and a high degree of impregnation $(>80 \%)(18)$.

Series B. Pellets with 45 wt\% glass and a high degree of impregnation were mixed with PA pellets to obtain a concentration range of $5,10,15,20,25$, and $30 \mathrm{wt} \%$.

Series C. Pellets were made in the melt impregnation setup with a fiber concentration of $13,20,30$, 35,43 , and 45 wt $\%$.

\section{Injection Molding}

The materials were injection molded into dumbbell-shaped tensile bars (ISO R527-type 2) on an Arburg Allrounder 221-55-250 with a $19 \mathrm{~mm}$ screw. To minimize fiber degradation, the lowest possible back-pressure ( $\sim 0$ bar) and screw speed $(50$ $\mathrm{rpm}$ ) was used; barrel temperatures were set to $290^{\circ} \mathrm{C}$. A low injection speed was used to obtain the highest possible orientation in the direction of flow. Impact bars were obtained from tensile bars by removing the clamping parts.

The convergence in the dumbbell mold inclines the fibers in the direction of flow (20-22), so a high fiber orientation is expected. Because of the small dimensions of the apparatus, extra fiber fracture might take place.

\section{Fiber Length}

Fibers, obtained after incinerating the matrix, were dispersed in a 1 wt\% solution of carboxy-methylcellulose in water. Some drops of this suspension were placed on a glass slide. After drying, the slides were projected on a digitizing tablet using a projector with a $30 \times$ magnification. The minimum fiber length that could be measured was $40 \mu \mathrm{m}$. The ends of each fiber were located with a magnetic pen and from this data a number average fiber length, $\bar{l}_{n}$, was calculated using the following equation:

$$
i_{n}=\frac{\sum^{i} n_{i} \cdot l_{i}}{\sum^{i} n_{i}}
$$

where $n_{i}$ is the number of fibers with length $l_{i}$ Roughly 500 fibers were measured for each formulation.

\section{Fiber Orientation}

Tensile bars were cut in half and polished, using metallographic techniques. The polished samples were placed under a microscope and photographed. On the photographs the number of fibers $(n)$ inclined in the direction of flow (angle with the main flow direction always $<30^{\circ}$ ) was studied. The analysis was carried out at five positions in the cross section (Fig. 1).

The orlentation fraction $\left(\eta_{o}\right)$ was calculated with:

$$
\eta_{o}=\frac{n}{n_{m}}
$$

where $n_{m}$, the maximum number of fibers per crosssectional area that can be inclined in the direction of flow, is given by:

$$
n_{m}=\frac{V_{f}}{\pi r_{f}^{2}}
$$

where $r_{f}$ is the fiber radius.

\section{Testing of Samples}

Prior to testing the samples were dried at $110^{\circ} \mathrm{C}$ for $16 \mathrm{~h}$ in a vacuum oven. Notched Charpy impact strengths were measured at room temperature using a Zwick impact testing machine. The machined notch, with a radius of $0.25 \mathrm{~mm}$, was kept at $0.6 \mathrm{~mm}$ (a fifth of the sample thickness). For the impact test the middle part of the tensile bar was used, which was 3 mm thick. In this way, the orientation in the samples was the same as in the tensile test.

Tensile tests were performed according to ISO R527 on an Instron machine with an elongation rate of 1 $\mathrm{mm} / \mathrm{min}$ using a strain gauge.
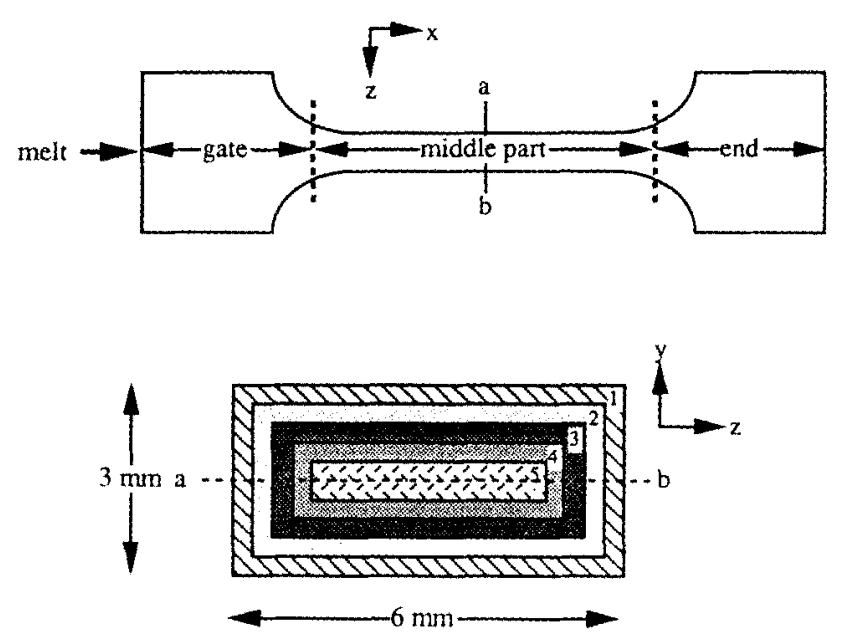

Fig. 1. Tensile sample (ISO R27-1) and cross section middle part $(1$ by $3 \mathrm{~mm})$. 


\section{Fractography}

Fracture surfaces were gold plated and examined with a Jeol T220A scanning electron microscope.

\section{RESULTS AND DISCUSSION}

\section{Samples}

Pellets of PA 6 with long glass fiber $(9 \mathrm{~mm})$ were produced by a continuous melt impregnation process $(19,20)$. Three series of materials were studied.

Series A evaluates how critical the degree of impregnation in the pellets is on the structure and properties of the injection molded bars. Pellets with 16 wt $\%$ glass ( $10 \mathrm{vol} \%$ ) with a low degree of impregnation $(<10 \%)$ and a high degree of impregnation ( $>80 \%$ ) were used for injection molding. The pellets with the low degree of impregnation showed pulled out fibers and many fibers remained in the collecting bag or hopper of the injection molding machine. As emphasized by McClelland (7), pellet-aesthetics is an important (commercial) parameter for injection moldable long fiber materials. The poorly chopped pellets were also found to obstruct the flow in the hopper.

In series B, the dilution of a mater batch is studied. Test bars were made from a mixture of 45 wt $\%$ glass pellets with high degree of impregnation and neat PA pellets. In this way the fiber concentration $5,10,15$, 20,25 , and $30 \mathrm{wt} \%$ were obtained.

In series $\mathrm{C}$ the fiber concentration is varied in the melt impregnation step and the influence of concentration on structure and properties is studied. Test bars were made with a fiber concentration of 13,20 , $30,35,43$, or $45 \mathrm{wt} \%$ with melt impregnated pellets of the appropriate glass concentration.

Samples with a high glass concentration, both for series $\mathrm{B}$ and $\mathrm{C}$, showed some jetting (20) at the entrance of the mold.

\section{Micro-structure}

\section{Fiber Concentration}

Of series A samples the fiber volume fraction, the fiber length, and the fiber orientation was measured at various parts of a tensile bar (Table 1). The concentration in the skin of the middle part was analyzed by grinding $2 \mathrm{~mm}$ from one side of the thickness of the bar, the concentration in the core by removing $1 \mathrm{~mm}$ from all sides.
In the direction of flow (gate $>$ middle $>$ end) no large concentration differences can be shown, suggesting that segregation due to the convergence in the tensile bar does not occur. The fiber concentrations in the skin and core are identical. Others (11, 12) observed significant skin-core concentration differences (twice higher in the core). There the injection molding was performed on larger machines. The poorly impregnated pellets showed some sample-tosample concentration variations. These concentration variations are probably due to the inhomogeneous nature of the pellets.

Concentration variations for series $B$ and $C$ materials, at different points in a tensile bar, were observed to be insignificantly small. For the mixtures (series B) the sample-to-sample concentration fluctuation were $\sim 5 \%$.

\section{Fiber Length}

The fiber length in the injection molding bars were analyzed after incinerating the polymer.

A typical example of a remaining glass fiber sample is shown in Fig. 2. Next to fibers small glass particles are visible. These small particles are shown in more detail in Fig. 3. Although difficult to observe, these fiber fragments have a length that is approximately twice the diameter of the fiber and are often more or less triangularly shaped.

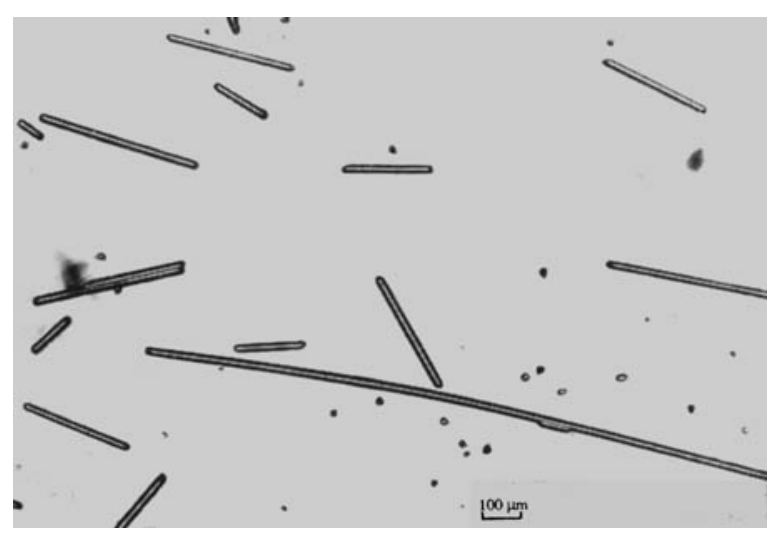

Fig. 2. Extracted glass fibers.

Table 1. Structure Series A samples. Fiber Volume Fraction $\left(V_{f}\right)$, Fiber Length $\left(I_{n}\right)$, and Fiber Orientation $\left(\eta_{0}\right)$ as Measured at Different Points in a Tensile Bar in the Direction of Flow (See Fig. 1).

\begin{tabular}{|c|c|c|c|c|c|c|}
\hline & \multicolumn{3}{|c|}{ Well Impregnated } & \multicolumn{3}{|c|}{ Poorly Impregnated } \\
\hline & $\begin{array}{c}V_{f} \\
(\text { vol. \%) }\end{array}$ & $\begin{array}{c}\bar{I}_{n} \\
(\mathrm{~mm})\end{array}$ & $\stackrel{n o}{(-)}$ & $\begin{array}{c}V_{t} \\
(\text { vol. } \%)\end{array}$ & $\begin{array}{c}\bar{l}_{n} \\
(\mathrm{~mm})\end{array}$ & $\eta_{0}$ \\
\hline$\overline{\text { gate }^{1}}$ & 10.2 & 0.90 & - & 9.6 & 0.81 & - \\
\hline middle part & - & - & 0.76 & - & - & 0.77 \\
\hline skin ${ }^{2}$ & 10.3 & 0.95 & 0.75 & 9.3 & 0.82 & 0.80 \\
\hline - core $^{3}$ & 10.2 & 0.85 & 0.79 & 9.3 & 0.79 & 0.69 \\
\hline end $^{1}$ & 10.3 & 0.85 & - & 9.5 & 0.82 & - \\
\hline
\end{tabular}

\footnotetext{
1) Total cross section.

2) Areas 1-3 (Fig. 1)
}

3) Areas 5 (Fig. 1 ). 


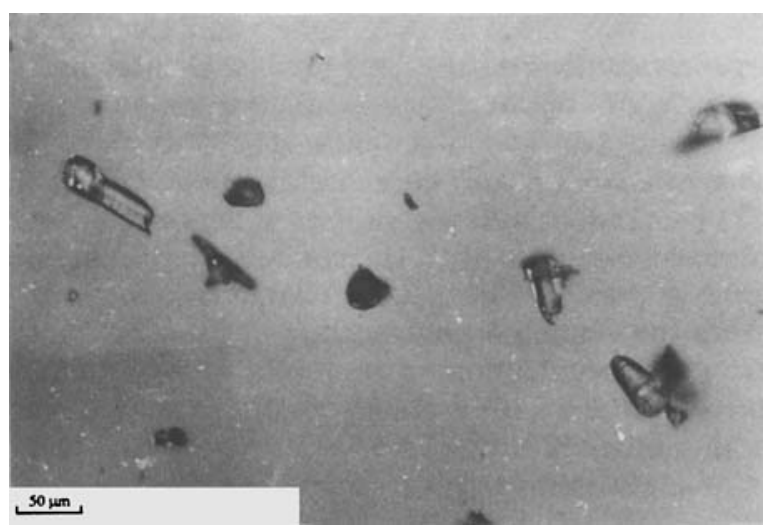

Fig. 3. Glass fiber fragments.

The number of small particles is present in nearly a one-on-one relation to the number of fibers. These triangular particles must have been formed by the fiber fracture in bending. In the fiber length analyses the small particles are disregarded. If the small particles had been taken into account, then the number average fiber lengths would approximately be halved. Ignoring fiber fragments is common in frequently used techniques to analyze fiber lengths, e.g., sieving (2). In the statistical descriptions of the fiber length distribution these particles are also excluded (23). Table 1 presents average fiber lengths at different points in tensile bars molded from series A materials. The fiber length is fairly constant over the samples. The size in the middle is not smaller than in the gate. So the convergence in the dumbbell does not degrade the fiber.

Variations in fiber length between the skin and core of the middle part is $\sim 10 \%$. This is much smaller than reported fiber length differences for long glass fiber reinforced polyamide (11) or polypropylene (12). Owing to the small dimensions of the injection molding apparatus used in this study, bundle flow cannot occur. This is possibly the reason that the fiber length differences between the skin and core are so small. Surprisingly the poorly impregnated pellets give similar results. On average the fibers in this study are almost twice as long as those that can be obtained by extrusion compounding (17).

Figure 4 gives average fiber lengths as a function of fiber concentration for injection molded series $B$ and $C$ materials. It is shown that with increasing concentration the fiber length decreases. Fibers longer than a millimeter are only present in samples with fiber volume fractions $<6$ vol\%. A decrease in fiber length with concentration has been observed with other matrices $(12,24,25)$ and is interpreted in terms of enhanced interactions between the fibers (collisions, spatial hindrance, friction) or a fiber and the matrix. Fiber fracture due to fiber-fiber friction seems unlikely, because here the fibers are protected by matrix material. Fiber lengths for series $B$ and $C$ materials are comparable. It is surprising that the series $B$ materials do not show a higher fiber breakdown. Ap-

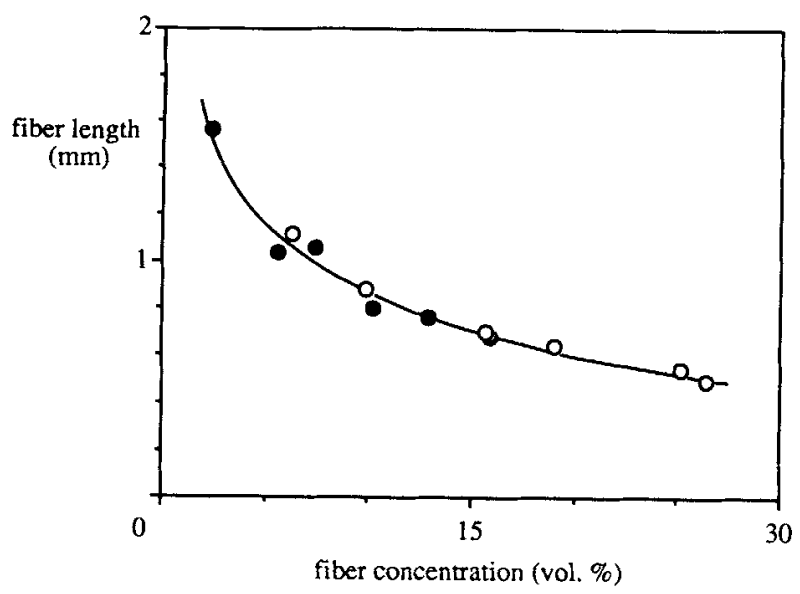

Fig. 4. Fiber length $v$ s. fiber concentration: - , series $B, O$, series $C$.

parently the concentration of the fibers in the pellets is not important, but the average concentration in the melt determines the amount of fiber fracture.

\section{Fiber Orientation}

Figures 5 and 6 give typical cross-sectional views. Examination reveals a high orientation of the fibers in the flow direction and an absence of fiber bundles. Although voids are common imperfections in composites $(24,26,27)$ especially at high fiber concentrations, they were not observed in this study.

Orientation measurements for samples molded from materials with a low and a high degree of impregnation (series A), show that $\sim 75 \%$ of the fibers incline more or less in the direction of flow (Table 1). This compares with reported orientation fractions for tensile bars $(28,29)$ and demonstrates the usefulness of the applied method. Here too the degree of impregnation in the pellets has little effect. On series A materials the orientation fractions were measured over the cross section (Fig. 7). For materials with the high degree of impregnation the orientation in the skin is lower than in the core with a maximum in between. In the materials with the low degree of impregnation the orientation in the skin is the same as in the middle.

The observed orientations can be understood from general flow models (20-22). A fiber orientation perpendicular to the main flow direction develops at the gate due to compressional flow. Near the convergence in the tensile bar, fibers align parallel to the flow lines, resulting in a higher orientation. The orienting capacity decreases when moving towards the center of the bar and thus orientation will be less in this region. Close to the mold wall, converging flow will not be experienced either, resulting in more perpendicular orientation (Figs. 5 and 6).

Figure 8 shows the average orientation fraction vs. the fiber concentration for series $\mathrm{B}$ and $\mathrm{C}$ materials. The average orientation fraction for all samples is 0.72 (dotted line in Fig. 8). Series B materials have a slightly lower orientation fraction compared to the 


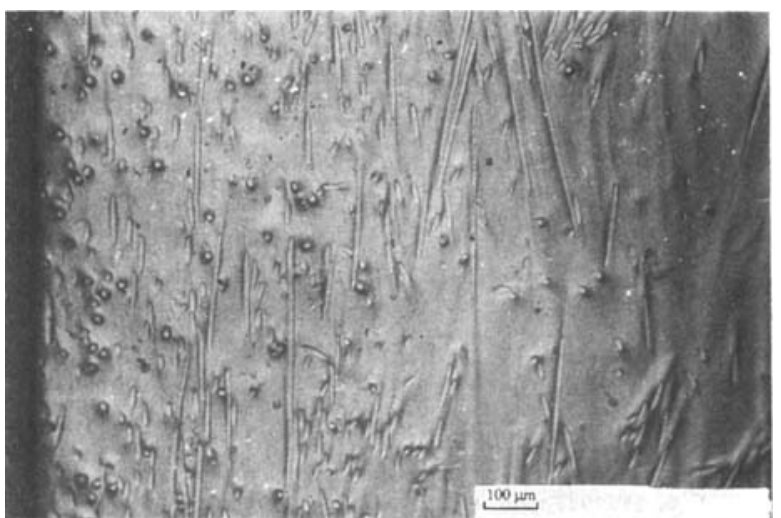

Fig. 5. Cross section parallel to the flow direction (skin at the left side; flow from bottom to top).

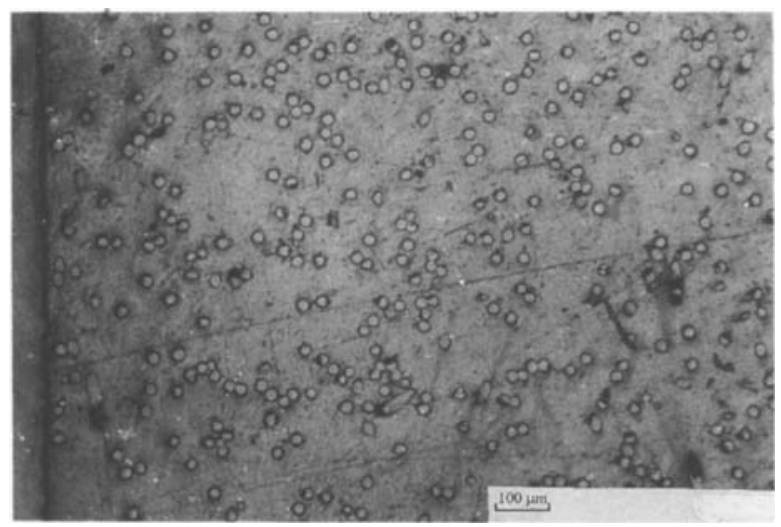

Fig. 6. Cross section perpendicular to the flow direction (skin at the left side; flow into paper).

series $\mathrm{C}$ systems. Increasing the concentration has no effect on the orientation. The reported effects of concentration show both an increase and decrease of fiber orientation $(12,17,28)$. An increase seems more logical, because with more fibers less space is available to pass the convergence in the dumbbell.

\section{Degree of Impregnation}

Samples are embedded in a fast curing acrylic resin (Technovit 4071 from Kulzer) and then ground and polished to smooth surfaces using metallographic techniques (18). The degree of impregnation is quantified by the percentage of wetted fibers shown on a polished surface (perpendicular to the fiber direction).

\section{Mechanical Properties}

\section{Notched Charpy Impact Strength}

The notched Charpy impact test was performed on the middle part of the tensile bars ( $3 \mathrm{~mm}$ thick). In this way the structure of the tensile and impact bar was the same.

The notched Charpy impact strengths for series A, poorly impregnated pellets are slightly lower than measured for pellets with a high degree of impregnation (Table 2). Possibly with optimizing the injection

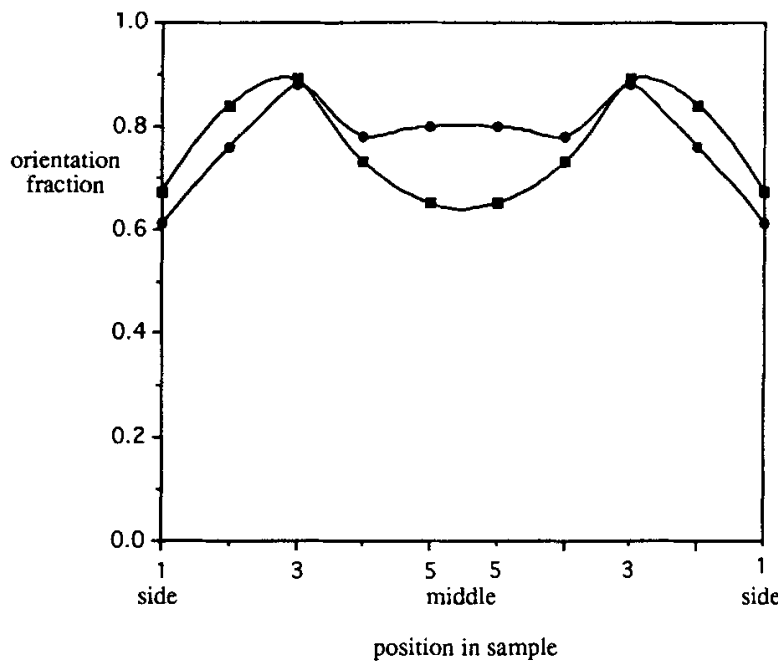

Fig. 7. Orientation over cross section in series A samples a high degree of impregnation pellets, 1 low degree of impregnation pellets.

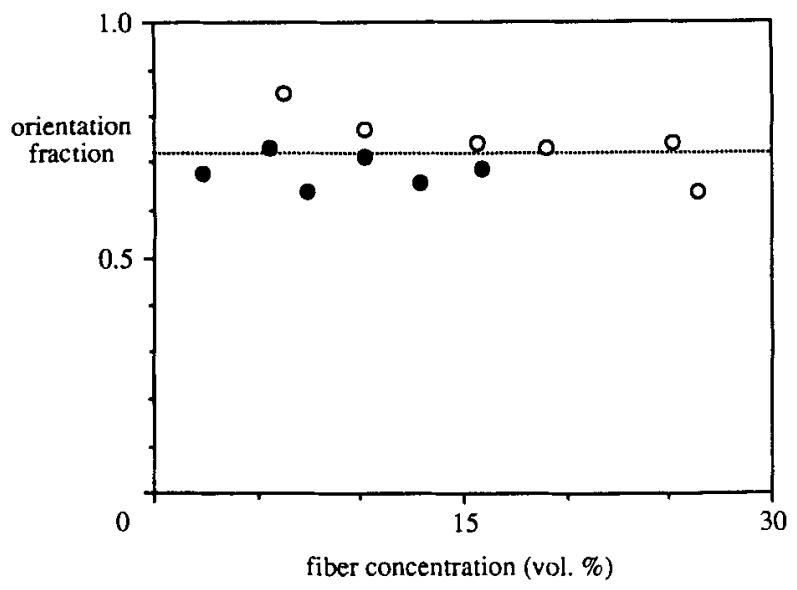

Fig. 8. Orientation $v$ s. fiber volume fraction: - series $B, O$, series $C$.

molding process the poorly impregnated pellets might give as good a product as the well impregnated pellets.

The notched Charpy impact strength for the series $\mathrm{B}$ and $\mathrm{C}$ increases linearly up to a fiber concentration of $16 \mathrm{vol} \%$ (Fig. 9). At higher concentrations a leveling off can be observed. This trend, was also observed with other short and long fiber reinforced thermoplastics $(12,17)$. The series B samples are comparable to the series $\mathrm{C}$ materials.

\section{Tensile Properties}

Table 2 shows the failure strength for series A materials. The failure strength of samples molded from poorly impregnated pellets is somewhat lower than measured for samples made from pellets with a high degree of impregnation. This may be attributed to the lower fiber concentration and fiber length observed for samples injection molded from poorly wetted pellets (Table 1), but also may be the result of a 
Table 2. Mechanical Properties of Series A Samples Molded From Materials With a High and a Low Degree of Impregnation.

\begin{tabular}{lccc}
\hline Degree of Impregnation (\%) & & $>80$ & $<10$ \\
\hline Failure strength & $(\mathrm{MPa})$ & 144 & 132 \\
Failure strain & $(\%)$ & 2.9 & 2.8 \\
Notched Charpy impact strength & $\left(\mathrm{kJ} / \mathrm{m}^{2}\right)$ & 12.0 & 10.6 \\
\hline
\end{tabular}

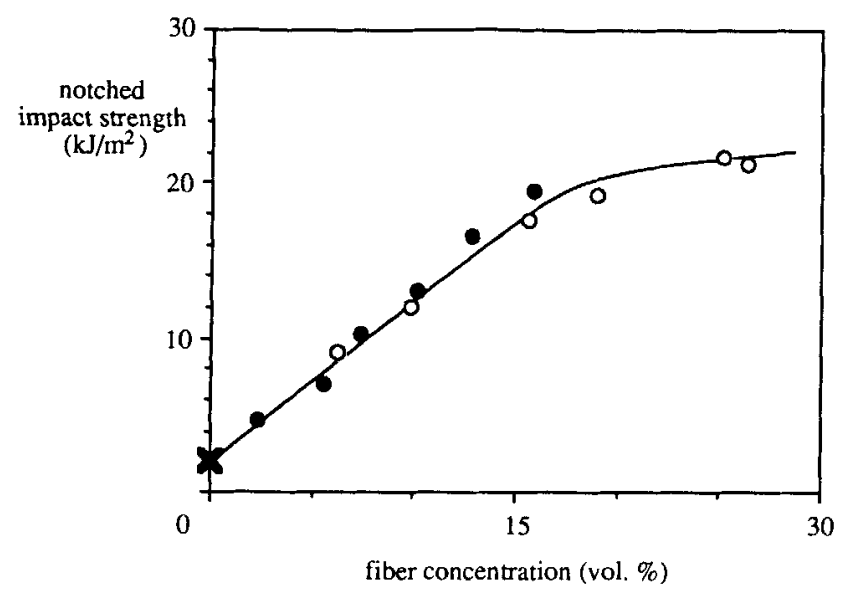

Fig. 9. Notched Charpy impact strength $v$ s. fiber volume fraction: - series $B, O$, Series $C, \times$, polyamide.

reduced interfacial adhesion, due to the lower fiber wetting in the material used at the beginning. The differences in the failure strain between these materials (Table 2) is small.

Figure 10 gives the failure strength of series $\mathrm{B}$ and $\mathrm{C}$ materials. It was observed that all samples, except for the neat PA $(0 \%)$, fractured in a brittle manner. The failure strength increases with the fiber concentration up to 20 vol\%, above which concentration a weak leveling off can be seen.

The series B materials have a slightly lower failure strength than the series $C$ materials. Furthermore, the sample-to-sample variation in the failure strength for the $\mathrm{B}$ materials was $10 \%$. These variations might be due to the observed concentration variations between the samples. The drawn lines in Fig. 10 are calculated lines whereby a critical fiber length is assumed $(0.4,0.6$, and $0.8 \mathrm{~mm})$.

The failure strain of the series $B$ and $C$ materials are given in Fig. 11. Failure occurs at strains equivalent or lower than the fiber failure strain (3\%). For both type of materials the failure strain decreases slightly with concentration (lines were calculated using linear regression). For short fiber reinforced polyamides, reported (29) failure strains frequently drop from $\sim 3 \%$, at a fiber concentration of 10 vol\%, to a strain $<2 \%$ with a concentration of 30 vol\%. It can further be observed that the failure strains for series $B$ materials are marked lower than for series $C$ materials.

The fibers in the fracture surface as studied with SEM, had a polymer layer on the fibers ( Fig. 12). This suggests that the fracture had taken place in the matrix.

\section{CONCLUSIONS}

Tensile bars were injection molded under mild conditions using long glass fiber reinforced polyamide pellets. In the tensile bar the observed fiber orientation was high, $\sim 70 \%$ of the fibers inclined in the direction of flow. The orientation of the fibers is near the skin higher than in the skin or in the core. The fiber length and concentration variations between the skin and core were found to be small. In the samples no fiber bundles were observed which might be due to the fact that we used a small injection molding machine. The fibers are well dispersed during the injection molding step, at the cost of fiber degradation. This results in shorter fibers than generally observed for long fiber systems. Next to fibers a high number of glass particles with a triangular shape were present. The total number of particles compares to the total number of fibers counted.

With increasing fiber concentration, the fiber orientation remained constant but the fiber length de-

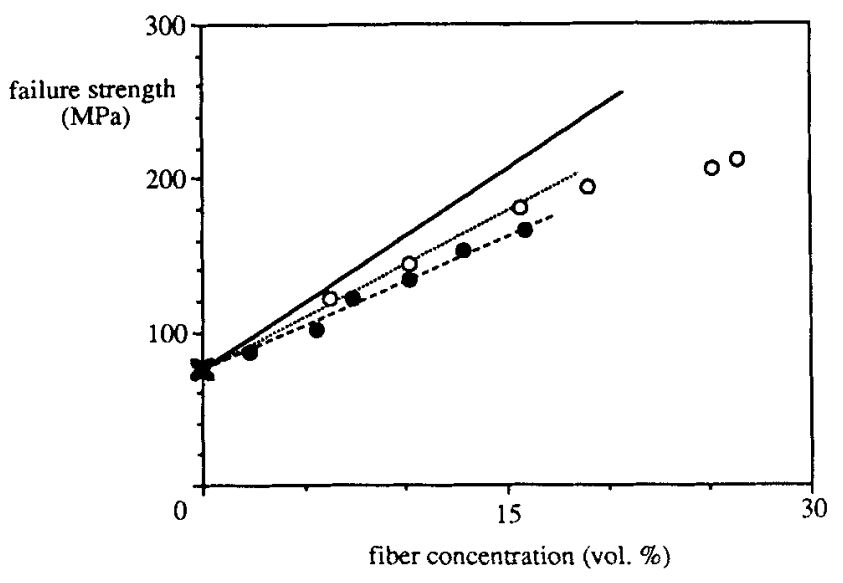

Fig. 10. Failure strength vs. fiber volume fraction: 0 , series $B$, $O$, series $C, \times$, polyamide, (lines calculated with rule of mixtures, as function of critical fiber length: from top, 0.4, 0.6, and $0.8 \mathrm{~mm}$.

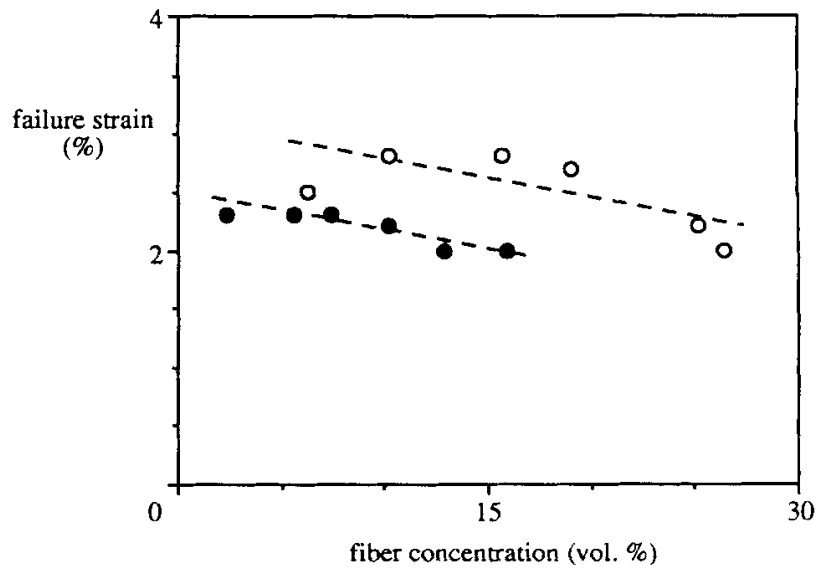

Fig. 11. Failure strain us. fiber volume fraction: - series $B$, $O$, series $C$. 


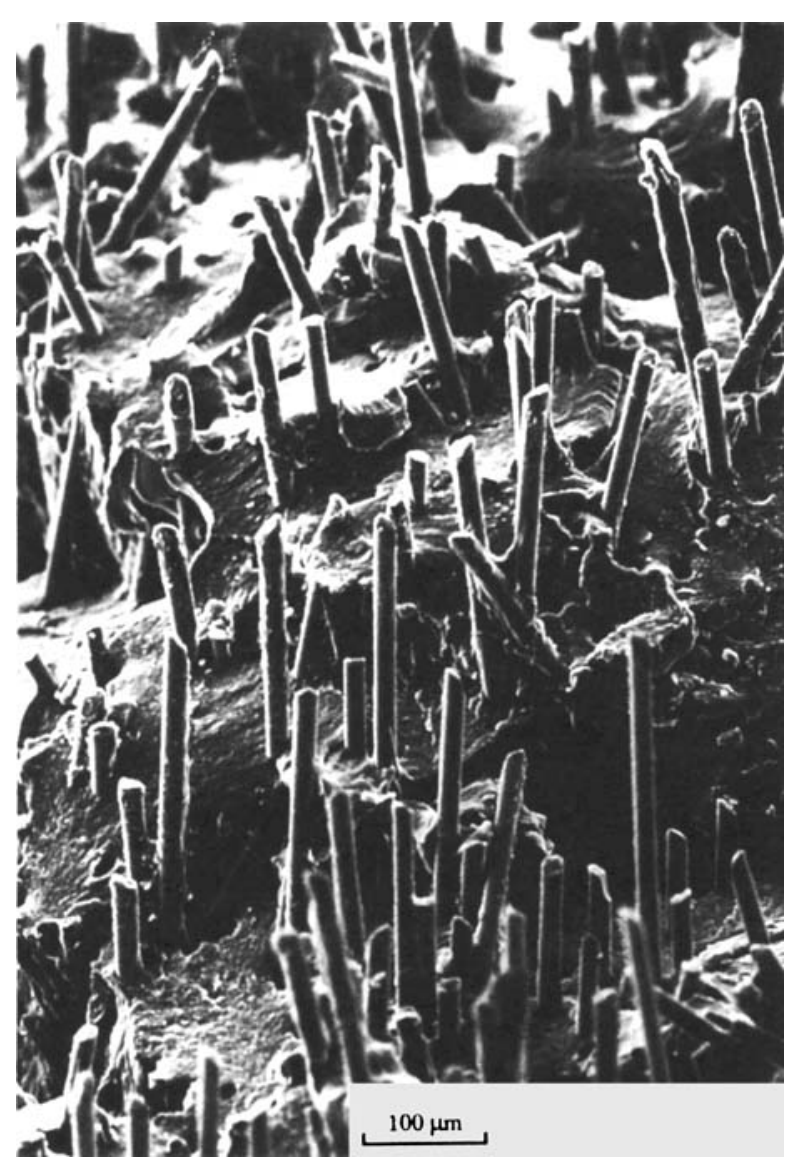

Fig. 12. SEM view of fracture surface.

creased considerably. With increasing fiber concentration the notched impact strength increased strongly as well as the failure stress. The strain to failure decreased slightly with concentration.

Injection molding with poorly wetted fibers, did increase the fiber break down. The impact and tensile properties were sightly lower. Possibly with some optimization of the injection molding process with the poorly wetted fibers, the properties of these samples might even approach those of the well-impregnated materials. Injection molding with a diluted master batch gave no significant changes in the structure. The impact properties were also unaffected by the diluting method, but the tensile properties somewhat lower. Here too optimizing the injection molding process might reduce the differences.

\section{ACKNOWLEDGMENT}

The authors acknowledge the Netherlands Innovative Research Program for Polymers, PPG Fiberglass, DSM, and Shell for financial support and the dona- tion of materials. The authors also thank Professor L. C. E. Struik for stimulating discussions.

\section{REFERENCES}

1. N. Raghupathi, in Composites Materials Technology: Pro cess \& Properties, P. K. Mallick and S. Newman, eds., Hanser Publishers, Munich (1990).

2. R. S. Bailey and H. Kraft, Intern. J. Polym. Proc., 2, 94 (1987).

3. D. A. Cianelly, J. E. Travis, and R. S. Bailey, Plastics Technol. 4, 83 (1988).

4. V. B. Gupta. R. K. Mittal, P. K. Sharma, G. Mennig, and J. Wolters, Polym. Compos., 10, 8 (1989).

5. B. Schmid, Kunststoffe, 79, 624 (1989).

6. A. G. Gibson and A. N. McClelland, presented PRI Conf. Fibre Reinforced Composites '86, Liverpool, U.K. (1986).

7. A. N. McClelland, PhD thesis, University of Liverpool, U.K. (1988).

8. R. K. Mittal, V. B. Gupta, and P. K. Sharma, Compos. Sci. Technol, 31, 295 (1988).

9. F. Flemming, Plaste Kautschuk, 20, 767 (1973).

10. J. Karger-Kocsis and K. Friedrich, Compos., 19, 105 (1988).

11. D. R. Moore, I. M. Robinson, and B. Slater, presented PRI Conf. Fibre Reinforced Composites '90, Liverpool, U.K. (1990).

12. D. A. Spahr, K. Friedrich, J. M. Schultz, and R. S. Bailey, J. Mater. Sci., 25, 4427 (1990).

13. B. Franzén, C. Klason, J. Kubát, and T. Kitano, Compos., 20, 65 (1989).

14. R. P. Hegler and G. Mennig, Polym. Eng. Sci., 25, 395 (1985).

15. R. S. Bailey, D. R. Moore, I. M. Robinson, and P. M. Rutter, presented PRI Conf. Fibre Reinforced Composites '91, Manchester, U.K. (1991).

16. W. J. Janosky, H. K. Watkins, and P. C. Gaa, SPE ANTEC Tech. Papers, 35, 613 (1989).

17. H. Bijsterbosch and R. J. Gaymans, to be published.

18. H. Bijsterbosch and R. J. Gaymans, Compos. Manuf., 4. 85 (1993).

19. H. Bijsterbosch and R. J. Gaymans, Compos. Manuf., 4, 133 (1993).

20. M. J. Folkes, Short Fiber Reinforced Thermoplastics, Research Studies Press, Oxford, U.K. (1982).

21. M. W. Darlington, P. L. McGinley, and G. R. Smith, Plastics Rubber: Mater. Appl, 2, 51 (1977).

22. P. F. Bright, R. J. Crowson, and M. J. Folkes, J. Mater. Sci., 13, 2497 (1978).

23. S. R. Doshi and J. M. Charrier, Polym. Compos., 10, 28 (1989).

24. J. Denault, T. Vu-Khanh, and B. Foster, Polym. Compos., 10, 313 (1989).

25. B. Fisa, in Composites Materials Technology: Process \& Properties, p. 265, P. K. Mallick and S. Newman, eds. Hanser Publishers, Munich (1990).

26. M. W. Darlington and G. R. Smith, Polymer, 16, 459 (1975).

27. A. Vaxman, M. Narkis, A. Siegmann, and S. Kenig, Polym Compos., 10, 449 (1989).

28. R. P. Hegler, V. Altstädt, G. W. Ehrenstein, G. Mennig, J. Scharschmidt, and G. Weber, Kunststoffe, 76, 766 (1986).

29. M. G. Bader and J. F. Collins, Fibre Sci. Technol., 18, 217 (1983).

Revised July 1994 